\title{
Güneş Pilleri Uygulamalarında Kullanılan Organik Tabanlı Schottky Diyotlarında İyonize Radyasyonun Aygıt Parametrelerine Etkisi
}

\author{
Serdar KARADENİ ${ }^{*}$, Behzad BARIŞ², Hande KARADENIZ ${ }^{3}$, Sema Bilge OCAK ${ }^{4}$, \\ A.Birkan SELÇUK ${ }^{5}$
}

$\ddot{O} \mathbf{z}$

$\mathrm{Bu}$ çalışmada, organik araüzeyli Schottky yapısına iyonize radyasyonun etkileri araştırılmıştır. Hazırlanan metal/koronen/n-Si Schottky yapılar, değişik dozlarda gama radyasyonuna maruz bırakılmış ve bu yapıların ışınlama öncesi ve sonrası performans parametrelerindeki değişimler incelenmiştir. Organik arayüzey tabaka olarak koronen malzemesi kullanılmıştır. Arayüzey malzemesi döndürme ile kaplama tekniği kullanılarak, değişik kimyasal yöntemlerle temizlenmiş olan n-tipi silisyum tabanlar üzerine ince film olarak kaplanmıştır. Yapıların radyasyon öncesi ve sonrası elektriksel karakteristiklerindeki değişimler karanlık ortamda ve oda sıcaklığında I-V, C-V ve G-V ölçüm teknikleri kullanılarak incelenmiştir.

Anahtar Kelimeler: Schottky diyot, koronen, iyonize radyasyon.

\section{The Effect of Ionizing Radiation on Device Parameters In Organic Based Schottky Diodes Used in Solar Cell Applications}

\begin{abstract}
In this study, the effects of ionizing radiation on organic interfaced Schottky diodes were investigated. The prepared $\mathrm{metal} /$ coronene/n-Si Schottky structures were exposed to different dose of gamma radiation and examined the variations of performance parameters of these structures before and after radiation. The coronene material was used as an organic interface layer and coated onto the n-type silicon substrates as a thin film by using the spin coating technique after various chemical cleaning methods. The changes in the electrical characteristic of the structures were investigated using the I-V, $\mathrm{C}-\mathrm{V}$ and G-V measurement techniques before and after irradiation in dark environment and at room temperature.
\end{abstract}

Keywords: Schottky diode, coronene, ionized radiation.

\footnotetext{
${ }^{1}$ Giresun Üniversitesi, Mühendislik Fakültesi, Giresun, Türkiye, serdar.karadeniz@giresun.edu.tr

${ }^{2}$ Giresun Üniversitesi, Fen-Edebiyat Fakültesi, Giresun, Türkiye, behzadbaris@yahoo.com

${ }^{3}$ Giresun Üniversitesi, Mühendislik Fakültesi, Giresun, Türkiye, hande.karadeniz@giresun.edu.tr

${ }^{4}$ Gazi Üniversitesi, Fen Bilimleri Enstitüsü, Ankara, Türkiye, sbocak@gazi.edu.tr

5̇̇zmir Bakırçay Üniversitesi, Mühendislik ve Mimarlık Fakültesi, İzmir, Türkiye, birkanselcuk@gmail.com

${ }^{1}$ https://orcid.org/0000-0002-1792-8134 ${ }^{2}$ https://orcid.org/0000-0003-3041-6413 ${ }^{3}$ https://orcid.org/0000-0002-1028-767X ${ }^{4}$ https://orcid.org/0000-0002-0590-7555 3 https://orcid.org/0000-0002-8632-3972
} 


\section{Giriş}

Metal/yariiletken (Schottky) yapılar yariletken malzemelerin karakterizasyonunda önemli araştırma aygıtlarıdır ve teknolojik olarak bazı yararlı cihazların üretilmesinde rol oynarlar. Bir metal bir yarıiletkene temas ettirildiğinde termal denge kuruluncaya kadar bu iki malzeme arasında taşıyıcı geçişleri meydana gelir. Her iki malzemenin yük alışverişi sonucunda Fermi enerji düzeyleri eşit olduğunda yeni bir yük dağılımı meydana gelir ve bir potansiyel engeli oluşur. Bu tip aygıtlarda metal ile yariletken arayüzeyinde bir potansiyel engel oluştuğunu ilk olarak Schottky (Schottky, 1938), meydana gelen bu potansiyelin, metal ile yariletkenin iş fonksiyonları arasındaki farktan kaynaklandığını ise Mott (Mott, 1939; Mott, 1938) ortaya atmıştır. Engelin omik ya da doğrultucu olması tamamen yarıiletkenin tipine, metalin ve yarıiletkenin iş fonksiyonlarına bağlıdır. Bir arayüzey tabaka metali yarıiletkenden yalıtmak amacı ile kullanıldığında ise oluşan metal/yalıtkan/yarıiletken yapılar, yarıiletken yüzeylerini incelemek için yararlı birer aygıt haline gelirler (Nicollian ve ark., 1982).

Son y1llarda güneş pili teknolojilerinde daha ucuz malzeme ile enerji elde etmek üzerine araştırmalar önem kazanmıştır. $\mathrm{Bu}$ konuda en uygun seçeneklerden birisi metal/yarıiletken yapılarında güneş pillerini kullanmaktır. Bu yapıların özelliği, bir yarıiletken üzerine sadece ince bir film kaplanması ve böylece daha ucuz ve az enerji üretimiyle yapılabilmeleridir. Bu aygıtların üretimi sırasında yüksek sıcaklık işlemleri uygulanmadığından, yapılar içerisindeki azınlık taşıyıcılarının özelliklerinde herhangi bir bozulma gözlenmez. Ancak bu tip yapıların güneş pili olarak karakteristikleri p-n eklem türündeki güneş pillerine göre daha kötüdür. Bunun sebebi, termoiyonik emisyon karanlık akımının oldukça yüksek olmasıdır. Termoiyonik emisyon karanlık akımı metal ile yarıiletken arasına ince bir arayüzey tabaka konularak azaltılabilir. Bu şekildeki yapılar metal/yalıtkan/yarıiletken (MYY) veya metal/oksit/yariletken (MOY) Schottky barrier olarak adlandırılır. Bu yapıların p-n eklemlere göre bazı avantajları vardır. Bunlardan en önemlisi, düşük sıcaklıklarda üretilebilmelerinden dolayı yüksek sıcaklıkta meydana gelebilecek katkılama etkilerinin ortadan kalkması ve böylece azınlık taşıyıcı ömürlerinin korunmasıdır.

Polisiklik aromatik hidrokarbonlar (PAH) organik yariiletken malzemeler olarak teknolojik öneme sahip olmalarından dolayı birçok çalışma gruplarının ilgisini çekmiştir. Bunlar, büyük kütleli molekülleri olan kararlı organik bileşiklerdir (Rawa-Adkonis ve ark., 2006; Payanan ve ark., 2013). Bu tip organik moleküller farklı optoelektronik özelliklere sahip olup, organik 1şı yayıcı diyotlar (OIYD), organik ince film transistörler (OIFT), organik ışık yayıcı transistörler (OIYT), Schottky engel diyodu (Yüksel ve ark., 2017; Yüksel ve ark., 2016) ve organik fotovoltaik hücreler (OPH) (Jiang ve ark., 2013; Zhan ve ark., 2014; Kido ve ark., 1994) gibi yüksek performanslı optoelektronik 
aygıtlarda kullanılmaktadır. Diğer taraftan ucuz bir teknoloji ve çevreci bir üretim süreciyle elde edilebilmeleri gibi avantajları vardır.

Koronen, $\mathrm{C}_{24} \mathrm{H}_{12}$ kimyasal formüllü altı tane peri-füzyonlu (kaynaşmış) benzen halkası içeren yoğunlaştırılmış aromatik hidrokarbondur (Barış ve ark., 2017; Fetzer, 2000). Koronen karpatit adı verilen bir mineral olarak da bilinir (Itoh, 2008). Yük taşıma mekanizması ve 1şık yayıcı kabiliyetinden dolayı optik ve organik elektroniğin ilgisi haline gelmiştir (Gregor ve ark., 2004; Ruifeng ve ark., 1999; Yıldırım, 2017). Bu yüzden birçok araştırmacı koronenin optik ve elektriksel özelliklerini araştırmıştır. Xiao ve arkadaşları (Xiao ve ark., 2011) ve Erdal (Erdal, 2020) nano-tel koronen yapılarının foto-anahtarlama ve 1 şık yayıcı özelliklerini rapor etmişlerdir. Zhang ve arkadaşları (Zhang ve ark., 1999) koronen moleküler filmlerinin organik ışık yayıcı diyotlar için bir yayıcı tabaka olabileceğini belirtmiştir.

Bu çalışmada, organik bir aratabaka olarak koronen malzemesi kullanılarak oluşturulan organik arayüzeyli Schottky yapılarının ışınlama öncesi ve sonrası elektriksel parametrelerindeki değişimler araştırılmıştır. Bu amaçla metal/koronen/n-Si yapıları üretilmiş ve bu yapıların radyasyon öncesi ve sonrası performans parametreleri üzerindeki değişimler oda sıcaklığında ve karanlık ortamda I-V, C$\mathrm{V}$ ve G-V teknikleri kullanılarak incelenmiştir.

\section{Materyal ve Metot}

Bu çalışmada metal-yalıtkan-yarıiletken yapıların üretiminde kullanılmak üzere Czochralski yöntemi ile büyütülmüş $500 \mu \mathrm{m}$ kalınlığında $50.8 \mathrm{~mm}$ çapında fosfor katkılı (100) düzleminde kesilmiş $1.2 \Omega$-cm özdirençli tek tarafı parlatılmış n-tipi Silisyum tek kristali kullanılmıştır. Organik arayüzeyli Schottky yapıları oluşturmak için kristaller ilk olarak bir dizi kimyasal işleme tabi tutulmuştur. Kimyasal temizlik işlemi biten kristaller, alt yüzeylerine omik kontakt oluşturmak üzere vakum sistemine yerleştirilmiş ve yaklaşık $2 \times 10^{-6}$ Torr basınçta ve 500 Å kalınlığında \%99.999'luk yüksek saflıktaki alüminyum (Al) metali kaplanmıştır. Omik kontağı oluşturulmuş kristallere döndürme yöntemiyle ince fillm kaplama işlemi yapmak için Laurell marka spin coater cihazı kullanılmıştır. Bir yüzeylerine koronen organik film kaplanan kristallerin üzerinde, doğrultucu kontaktların oluşturulması vakum ortamında sağlanmıştır. Kristallerin organik ince film kaplı yüzeyleri üzerine bir maske yerleştirilmiş ve yaklaşık $2 \times 10^{-6}$ Torr basınçta $1500 \AA$ kalınlığında \%99.99'luk altın (Au) kaplamak suretiyle 1.2 mm çapında doğrultucu kontaktlar oluşturulmuştur. Şekil 1'de üretilen organik arayüzeyli $\mathrm{Au} / \mathrm{koronen} / \mathrm{n}-\mathrm{Si} / \mathrm{Al}$ diyodunun şematik diagramı görülmektedir. 


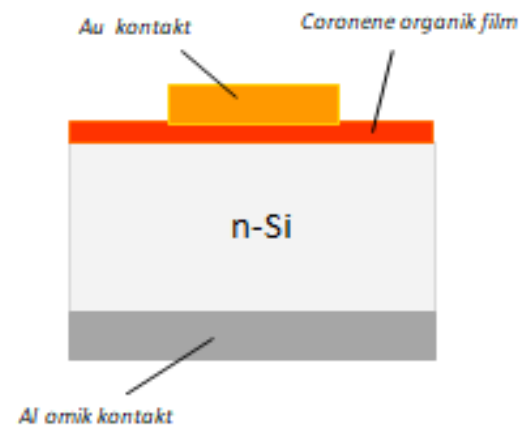

Şekil 1. Üretilen $\mathrm{Au} / \mathrm{koronen} / \mathrm{n}-\mathrm{Si} / \mathrm{Al}$ diyodunun şematik diyagramı.

Yapıların akım-gerilim ölçümleri Keithley 2410 SourceMeter kullanılarak yapılmıştır. Kapasite-gerilim (C-V) ve iletkenlik-gerilim (G-V) ölçümleri HP 4192A LF impedans analizörü ile gerçekleştirilmiş olup, test sinyali olarak $1 \mathrm{MHz}$ frekansında ve $40 \mathrm{mV}_{\mathrm{rms}}$ değerinde bir sinüzoidal gerilim kullanılmıştır. Ölçümler radyasyon öncesi ve sonrası olmak üzere oda sıcaklığında ve karanlık ortamda alınmıştır. Üretilen Au/koronen/n-Si/Al yapıları ${ }^{60} \mathrm{Co}$-gama kaynağ kGy dozlarda iyonize radyasyona maruz bırakılmıştır.

Yapıların oda sıcaklığındaki ölçümlerinden ideallik faktörü, doyma akımı, sıfır beslem engel yüksekliği, seri direnci, difüzyon potansiyeli, verici yoğunluğu, tüketme tabakası genişliği, elektrik alanı, Schottky engel alçalması ve $\mathrm{C}_{2}$ parametreleri belirlenmiştir. Ayrıca kristal temizlenmesi ve aygıtların hazırlanması sırasında kristalin yasak enerji aralığında istenmeden oluşan arayüzey durum yoğunluklarının yasak enerji bant aralığındaki dağılım profili ve ortalama arayüzey yoğunluk değerleri elde edilmiştir. Yapıların seri direnç değerleri gelişmiş Norde yöntemi kullanılarak hesaplanmıştır.

\section{Bulgular ve Tartışma}

Şekil 2'de Au/koronen/n-Si/Al yapılarının oda sıcaklığında 0 ile $3 \mathrm{~V}$ aralığında alınmış iyonize radyasyon öncesi ve sonrası akım-gerilim eğrileri görülmektedir. Şekil 2'den görüldüğü üzere 0.1 $0.25 \mathrm{~V}$ aralığında bir çizgisel bölgenin olduğu gözlenmiş olup, bu beslem bölgesinde yapının akımgerilim arasındaki bağıntı (Card ve ark., 1971),

$$
\mathrm{I}=\mathrm{I}_{\mathrm{o}}\left[\exp \left(\frac{\mathrm{qV}}{\mathrm{nkT}}\right)-1\right]
$$


ifadesiyle verilmektedir (Rhoderic ve ark., 1988). Burada $I_{0}$, çoğunluk taşıyıcıları için ters doyma akımı ve n, diyot ideallik faktörü olup, Termoiyonik Emisyon (TE) akımının etkin olduğu durumda,

$$
I_{o}=A A^{*} T^{2} \exp \left(\frac{-q \Phi_{B}}{k T}\right)
$$

bağıntısıyla verilir. Burada $\mathrm{A}, \mathrm{A}^{*}$ ve $\Phi_{\mathrm{B}}$ terimleri sırasıyla diyot alanı, Richardson sabiti ve engel yüksekliğidir.

Çizgisel eğrinin akım eksenini kestiği noktadan $\mathrm{I}_{0}$ doyma akımı değeri ve engel yüksekliği elde edilmiştir. İdeallik faktörü, deşiklerin oksit tünelleme ihtimali 1 kabul edilerek, LnI-V eğrisinin eğiminden (2) denklemi yardımıyla hesaplanmıştır. İyonize radyasyon dozuna bağlı olarak $\mathrm{Au} /$ koronen/n-Si/Al yapıların n, $\mathrm{I}_{\mathrm{o}}$ ve $\Phi_{\mathrm{B}}$ (I-V) değerleri Tablo 1'de verilmiştir. Şekil 2'ye bakıldığında düz beslem bölgesinde iyonize radyasyonun yapının akım-gerilim eğrilerine sistematik bir etkisi olduğu görülmektedir. Radyasyon dozlarındaki artışlar Au/koronen/n-Si/Al diyot yapısında hasar meydana getirmiş, akım değerleri azalmış ve buna bağlı olarak minimum akım değeri 3.79x 10 4 A bulunmuştur. Düz beslem bölgesindeki akım azalmaları, yasak bant aralığındaki gama radyasyonunun neden olduğu kusurlarla ilişkilendirilebilir. Bu kusurlar, serbest yük taşıyıcılarının yakalanmasına ve seri direncin artmasına sebep olur. Gama dozları arttıkça kusurların yoğunluğu da artmış ve düz beslem akım değerlerinin azalmasına neden olmuştur (Lin ve ark., 2010; Tataroglu ve ark., 2006).

Yapıların radyasyon öncesi oda sıcaklığındaki akım-gerilim eğrilerinden elde edilen ideallik faktörünün 1 'den çok büyük ve LnI-V eğrilerindeki lineerliliğin genelde çok küçük bir gerilim bölgesinde olması, yapıların akım mekanizmasında termiyonik emisyon veya azınlık taşıyıcı enjeksiyonunun etkin olması ihtimalini güçlendirmektedir (Kar ve ark., 1980). Kümülatif doz artışını takiben yapıların ideallik faktöründe artış, engel yüksekliklerinde ise azalma gözlenmiştir. Aygıtın elektriksel özelliklerinin kötüleşmesinin sebebi koronen organik ince filmin içerisinde bulunan karbon ve hidrojen bağlarının iyonize radyasyon tarafından kırılarak yapıda kusurlar oluşturması olarak düşünülebilir. Öte yandan ışınlama sırasında tuzak formunda ve aktif olan diğer gizli kusurlar da aygit parametrelerinin bozulmasindan sorumludur (Arshak ve ark., 2004). 


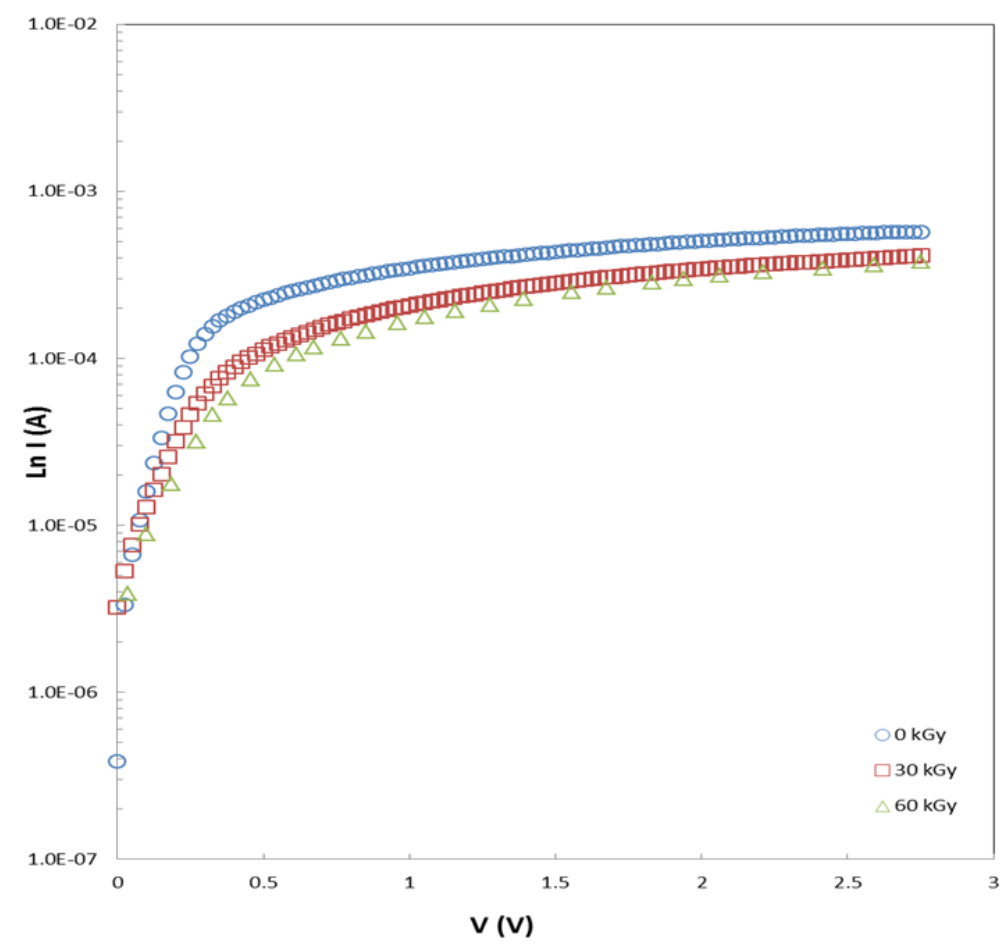

Şekil 2. Au/koronen/n-Si/Al yapılarının oda sıcaklığındaki radyasyon öncesi ve sonrası düz beslem I- $\mathrm{V}$ eğrileri.

$\mathrm{Au} / \mathrm{koronen/n-Si/Al} \mathrm{yapılarının} \mathrm{oda} \mathrm{sıcaklığındaki} \mathrm{radyasyon} \mathrm{öncesi} \mathrm{engel} \mathrm{yüksekliği} 0.640 \mathrm{eV}$ olup, artan radyasyon dozlarıyla azalmıştır. Tablo 1'den görüldüğü üzere Au/koronen/n-Si/Al yapısının radyasyon sonrası engel yüksekliği değerleri $0.542 \mathrm{eV}$ 'a doğru azalma göstermiştir. Bazı araştırmacıların (Mamor ve ark., 2007; Grussell ve ark., 1980) rapor ettiği üzere, bu durum radyasyona maruz bırakılan n-tipi veya p-tipi Schottky yapılarının bant aralığında serbest taşıyıcı konsantrasyonuna etki eden kusurlar yaratmakta ve engel yüksekliğini azaltmakta veya arttırmaktadır.

Tablo 1. Au/koronen/n-Si/Al yapılarının iyonize radyasyon dozuna bağlı n, $\mathrm{I}_{\mathrm{o}}$ ve $\Phi_{\mathrm{B}}(\mathrm{I}-\mathrm{V})$ değerleri.

\begin{tabular}{|c|c|c|c|}
\hline \hline Doz $(\mathrm{kGy})$ & 0 & 30 & 60 \\
\hline $\mathrm{n}$ & 2.83 & 4.31 & 5.21 \\
\hline $\mathrm{I}_{\mathrm{o}}\left(\mathrm{x} 10^{-6} \mathrm{~A}\right)$ & 3.20 & 5.06 & 5.65 \\
\hline$\Phi_{\mathrm{B}(\mathrm{I}-\mathrm{V})}(\mathrm{eV})$ & 0.640 & 0.585 & 0.542 \\
\hline \hline
\end{tabular}

Metal/yarıiletken yapıların elektriksel karakteristiklerinin tayininde seri direnç $\left(R_{s}\right)$ önemli bir parametredir. Seri direnç, silisyum kristali üzerinde oluşturulmuş omik (arka) kontak, gövde ile omik kontak arasında oluşmuş bir kirli bir film tabakası, doğrultucu kontağın hemen altında bulunan silisyum yüzey kıyısındaki tüketme tabakası ve gövde direnci, yarıiletken içerisindeki homojen dağılmayan safsızlık dağılımı gibi birçok nedenden ötürü meydana gelebilir. Seri direnç etkisi 
altındaki bir Schottky diyodunun termiyonik emisyon modeli ile düz beslem I-V özellikleri (Rhoderick ve ark., 1988),

$$
\mathrm{I}=\mathrm{I}_{\mathrm{o}}\left[\exp \left(\frac{\mathrm{q}\left(\mathrm{V}-\mathrm{I} R_{\mathrm{S}}\right)}{\mathrm{nkT}}\right)\right]
$$

ifadesi ile verilir. Buradaki $\mathrm{IR}_{\mathrm{S}}$ terimi, diyotun seri direnci üzerindeki voltaj düşmesidir. Yapıların seri direncinin hesaplanmasında, ideallik faktörünün 1'den çok büyük olması durumu için modifiye edilmiş Norde fonksiyonları (Bohlin, 1986),

$$
\begin{aligned}
& \mathrm{F}(\mathrm{V}, \gamma)=\mathrm{F}_{\mathrm{R}}(\mathrm{V})=\frac{\mathrm{V}}{\gamma}-\frac{1}{\beta} \operatorname{Ln}\left(\frac{\mathrm{V}}{\mathrm{RAA}^{*} \mathrm{~T}^{2}}\right) \\
& \Phi_{\mathrm{B}}=\mathrm{F}\left(\mathrm{V}_{\text {min }}, \gamma\right)-\left(\frac{1}{\gamma}-\frac{1}{\mathrm{n}}\right) \mathrm{V}_{\text {min }}-\frac{(\gamma-\mathrm{n})}{(\beta \mathrm{n})} \\
& \mathrm{R}_{\mathrm{S}}=\left(\frac{\gamma-\mathrm{n}}{\beta \mathrm{I}_{\text {min }}}\right)
\end{aligned}
$$

kullanılmıştır. Burada Norde fonksiyonunun ilk terimi olan V/2 ifadesi yerine $\mathrm{V} / \gamma$ terimini kullanmış olup, $\gamma$ ideallik faktöründen küçük olmamak üzere $(1<\mathrm{n}<\gamma)$ keyfi bir sabit sayıdır. Deneysel sonuçlardan seri direncin küçük olmadığı ve artan radyasyon dozu ile artış gösterdiği görülmüştür. Şekil 3'de düz beslem I-V ölçüm verilerinden faydalanılarak değişik radyasyon dozları için F(V) -V eğrileri verilmiştir. Şekil 3'den görüldüğü üzere Norde fonksiyonları yaklaşık $0.2 \mathrm{~V}$ değerinde bir minimumdan geçmektedir. Bu minimum nokta $\mathrm{V}_{\min }$ ve $\mathrm{I}_{\text {min }}$ 'a karşılık gelen $\mathrm{F}\left(\mathrm{V}_{\min }\right)$ noktasıdır. Tablo 2'de iyonize radyasyon dozuna bağlı olarak Au/koronen/n-Si/Al yapıların modifiye edilmiş Norde yöntemi kullanılarak hesaplanmış $\mathrm{R}_{\mathrm{s}}$ ve $\Phi_{\mathrm{B}}(\mathrm{I}-\mathrm{V})$ değerleri verilmektedir. Tablo 2'den görüldüğü üzere radyasyon dozunun kümülatif artışıyla yapıların seri direnç değerlerinde güçlü bir artış gözlenmektedir. Bu durum iyonize radyasyon tarafından yaratılan kusurlar yüzünden serbest taşıyıcı üretiminin ve konsantrasyonunun azaldığını, dolayısıyla da yarıiletkenin özdirencinin arttığını göstermektedir. 


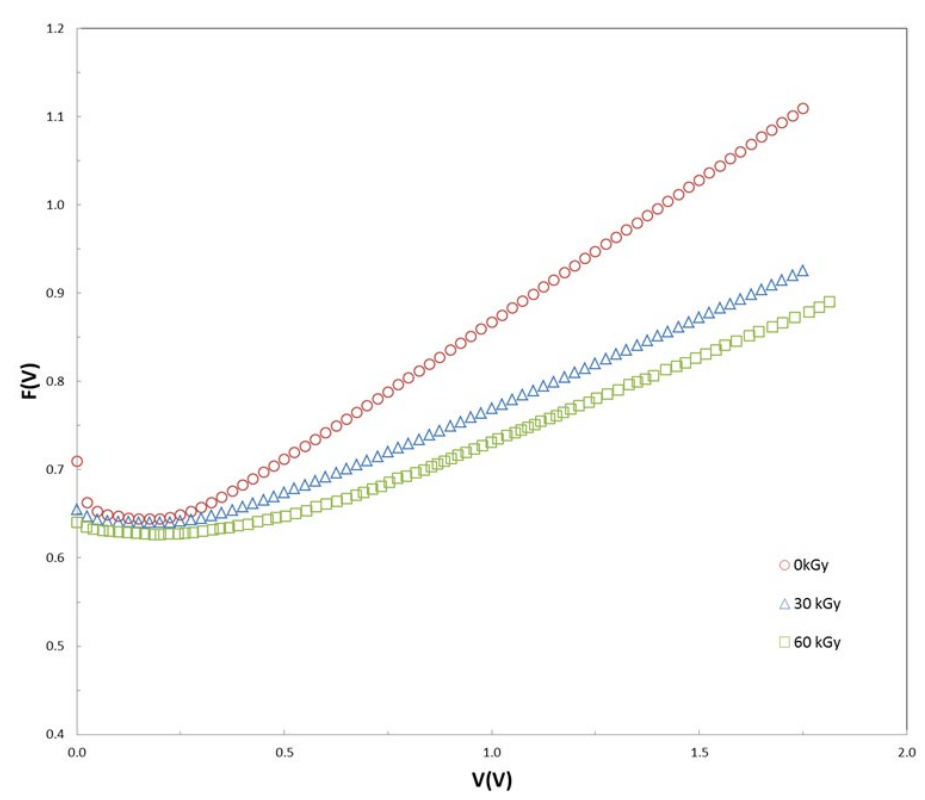

Şekil 3. Au/koronen/n-Si/Al yapılarının oda sıcaklığındaki radyasyon öncesi ve sonrası $F(V)-V$ eğrileri.

Tablo 2. İyonize radyasyon dozuna bağlı olarak Au/koronen/n-Si/Al yapıların Norde yöntemi kullanılarak hesaplanmış seri direnç ve engel yüksekliği değerleri.

\begin{tabular}{|c|c|c|c|}
\hline \hline Doz $(\mathrm{kGy})$ & 0 & 30 & 60 \\
\hline $\mathrm{R}_{\mathrm{s}}(\Omega)$ & 169.2 & 230.4 & 298.3 \\
\hline$\Phi_{\mathrm{B}(\mathrm{Norde})}(\mathrm{eV})$ & 0.652 & 0.593 & 0.554 \\
\hline
\end{tabular}

Arayüzey tabakasına sahip ve idealite faktörü 1'den büyük bir Schottky diyodunun arayüzey durumları (yariiletkenle dengede olan durumlar için) (Card ve ark., 1971),

$$
\mathrm{n}=1+\frac{\delta}{\varepsilon_{\mathrm{i}}}\left(\frac{\varepsilon_{\mathrm{s}}}{\mathrm{W}_{\mathrm{D}}}+\mathrm{qN}_{\mathrm{ss}}\right)
$$

şeklinde verilir. Burada $W_{D}$, tüketme bölgesi genişliği, $\delta$, arayüzey tabakası kalınlığg, $\varepsilon_{\mathrm{s}}$ ve $\varepsilon_{\mathrm{i}}$ S1rasıyla yarıiletkenin ve arayüzey tabakasının dielektrik sabitleri ve $\mathrm{N}_{\mathrm{ss}}$, arayüzey durumlarıdır. N-tipi bir yarıiletken için, iletkenlik bandının altından itibaren arayüzey durumlarının enerjisi ( $\left.\mathrm{E}_{\mathrm{ss}}\right)$ (Singh, 1985),

$$
\mathrm{E}_{\mathrm{c}}-\mathrm{E}_{\mathrm{ss}}=\mathrm{q}\left(\Phi_{\mathrm{e}}-\mathrm{V}\right)
$$

ile ifade edilir. Burada $E_{c}$, iletkenlik bant enejisi ve $\Phi_{e}$, efektif engel yüksekliğidir. Şekil 4'de $\mathrm{Au} / \mathrm{koronen} / \mathrm{n}-\mathrm{Si} / \mathrm{Al}$ yapılarının ideallik faktörüne bağlı arayüzey durumlarından yararlanılarak elde 
edilmiş değişik radyasyon dozları için arayüzey enerji dağılım profili görülmektedir. Şekil 4'e bakıldığında iyonize radyasyonun yapının enerji dağılım profili üzerinde sistematik bir etkisi olduğu açıkça görülmektedir. Radyasyon dozunun kümülatif artışıyla arayüzey durum yoğunluklarında artış gözlenmektedir. İyonize radyasyon, ev sahibi atomların yer değiştirmesine ve bunun sonucunda boşlukların, ara yüzey durumlarının ve diğer kusurların oluşmasına sebep olmuştur (Saqri ve ark., 2015; Auret ve ark., 1993; Auret ve ark., 1994). Diğer taraftan, arayüzey tuzak yoğunluğu Fermi seviyesi kıyısından iletim bandına doğru gidildikçe artmaktadır. Arayüzey durum yoğunluklarındaki bu artış yeniden birleşme merkezlerindeki artışa atfedilebilir.

Şekil 4'de görüldüğü üzere Au/koronen/n-Si/Al yapılarının radyasyon öncesi arayüzey durum yoğunluklarının $\left(E_{c}-0.613\right) \mathrm{eV}$ ile $\left(E_{c}-0.642\right) \mathrm{eV}$ arasında sırasıyla $2.60 \times 10^{11}$, den $3.82 \times 10^{11} \mathrm{eV}^{-}$ ${ }^{1} \mathrm{~cm}^{-2}$ değerine doğru eksponansiyel olarak artttığı gözlemlenmiş olup, radyasyon sonrası eğrilerde de benzer bir davranış göstermektedir. Ortalama arayüzey durum yoğunlukları 0, 30 ve 60 kGy'lik radyasyon dozları için sırasıyla $2.18 \times 10^{11}, 3.94 \times 10^{11}$ ve $5.02 \times 10^{11} \mathrm{eV}^{-1} \mathrm{~cm}^{-2}$ bulunmuştur.

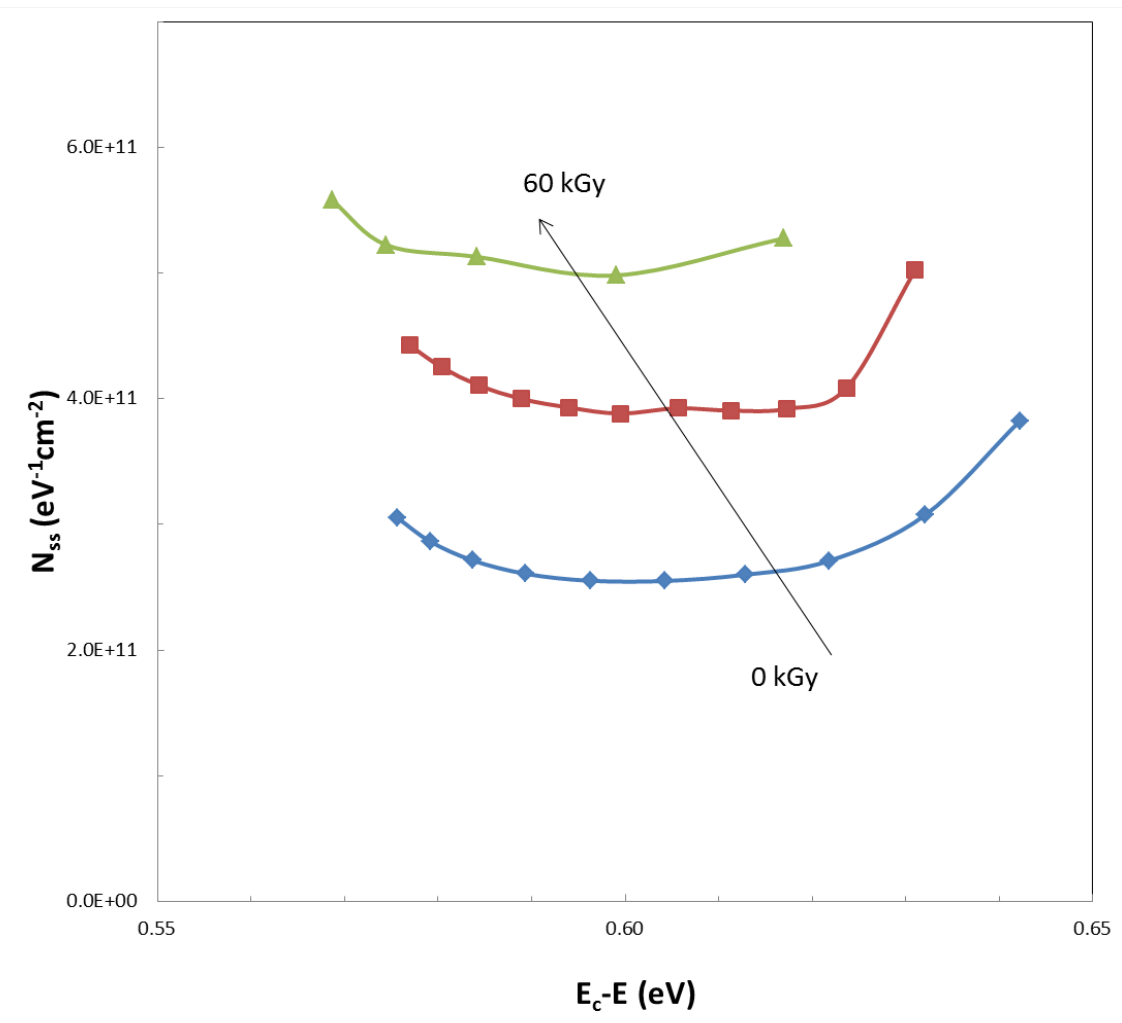

Şekil 4. Au/koronen/n-Si/Al yapılarının oda sıcaklığındaki radyasyon öncesi ve sonrası arayüzey enerji dağılım profilleri.

Şekil 5'de Au/koronen/n-Si/Al yapılarının oda sıcaklığında -3 ile 5V aralığında alınmış iyonize radyasyon öncesi ve sonrası kapasite-gerilim $(\mathrm{C}-\mathrm{V})$ eğrileri görülmektedir. Daha küçük frekanslarda daha uzun zaman sabitine sahip arayüzey durumları ölçülebilir. Ancak bu durumda $\mathrm{C}^{-2}-\mathrm{V}$ eğrisinin eğiminden elde edilecek alıcı yoğunluğu değeri gerçek değeri yansıtmaz. Yüksek frekanslarda 
arayüzey durumları uygulanan sinyali takip edemez ve böylece kapasiteye katkıda bulunamaz. Taşıyıcı yoğunluğu hesaplanacak olan kapasite-gerilim eğrisinin en az 100 kHz'de çizilmiş olması gereklidir (Kar, 1985).

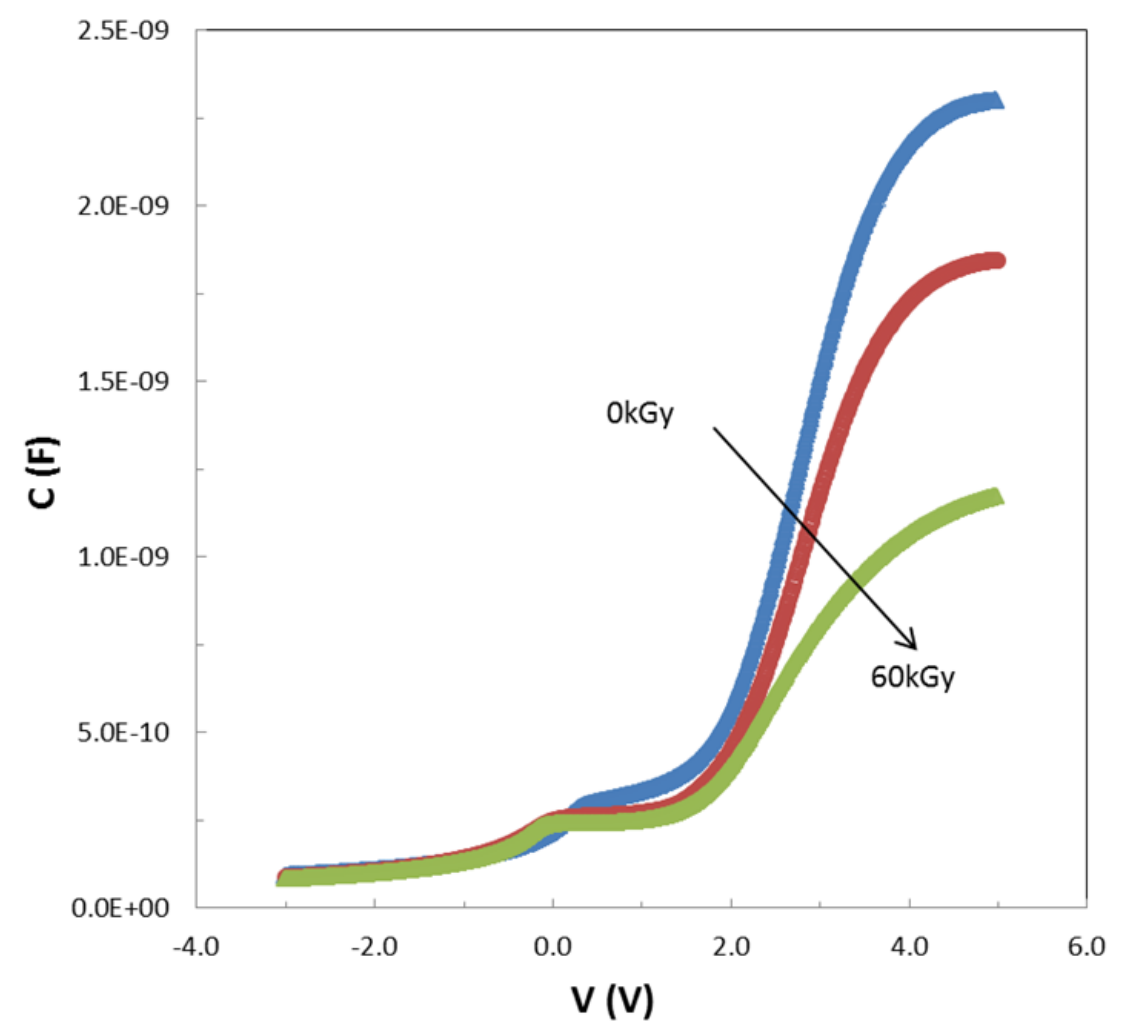

Şekil 5. Au/koronen/n-Si/Al yapılarının oda sıcaklığındaki radyasyon öncesi ve sonrası kapasitegerilim eğrileri.

Şekil 5'de görüldüğü üzere radyasyon öncesi ve sonrası kapasite eğrilerinde küçük pikler gözlemlenmektedir. Bu durum, organik/n-Si arayüzeyinde doğal oksit tabakasından ve ince organik tabakadan meydana gelmiş lokalize durumlara atfedilebilir (Jun, 2007). Diğer taraftan, $\mathrm{Au} /$ koronen/n-Si/Al yapılarının kapasite değerlerinde iyonize radyasyon sonrası azalma gözlenmektedir. Bunu sebebi olarak metal/yarıiletken arayüzeyindeki dielektrik sabitinde oluşan değişim (Singh ve ark., 2001; Karatas ve ark., 2005) veya iyonize katkı konsantrasyonunun radyasyon etkisine bağlı olarak azalması (Grussell ve ark., 1980) gösterilebilir. Yapıya uygulanan gerilimle tüketme bölgesinde oluşturulmuş ve elektronlarla yeniden birleşmiş deşikler sonucu hareketli taşıyıcıların yoğunluğundaki azalma da sebepler arasında sayılabilir.

$\mathrm{Au} / \mathrm{koronen} / \mathrm{n}-\mathrm{Si} / \mathrm{Al}$ yapılarının $\Phi_{\mathrm{B}(\mathrm{C}-\mathrm{V})}$ sıfır beslem engel yüksekliği, $\mathrm{V}_{\mathrm{d}}$ difüzyon potansiyeli, $\mathrm{N}_{\mathrm{d}}$ verici yoğunluğu, $\mathrm{W}_{\mathrm{D}}$ tüketme tabakası genişliği, $\mathrm{E}_{\mathrm{m}}$ elektrik alanı, $\Delta \Phi_{\mathrm{B}}$ Schottky engel alçalması ve $\mathrm{C}_{2}$ parametrelerini belirlemek üzere oda sıcaklığında radyasyon öncesi ve sonrası $1 \mathrm{MHz}$ frekansında $C^{-2}-\mathrm{V}$ eğrileri çizilmiştir (Şekil 6). 


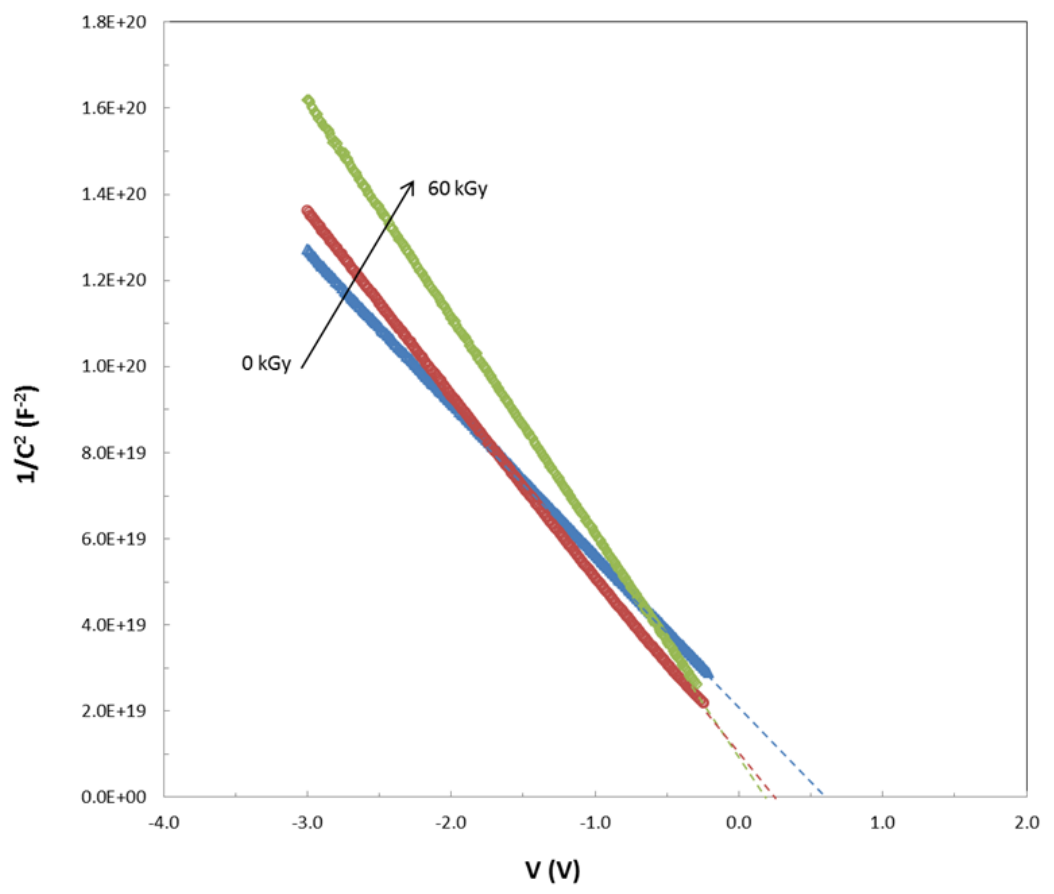

Şekil 6. Au/koronen/n-Si/Al yapılarının oda sıcaklığında radyasyon öncesi ve sonrası $1 / \mathrm{C}^{2}-\mathrm{V}$ eğrileri.

$\mathrm{C}^{-2}-\mathrm{V}$ eğrilerinin gerilim eksenine ekstrapole edilmesiyle, $\mathrm{V}_{\mathrm{o}}$ kesme gerilimleri, bu doğruların eğimlerinden ise $\mathrm{N}_{\mathrm{d}}$ verici yoğunlukları hesaplanmıştır. $\mathrm{V}_{\mathrm{o}}$ ile $\mathrm{V}_{\mathrm{d}}$ arasındaki bağıntı arayüzey durumları yokken,

$$
\mathrm{V}_{\mathrm{o}}=\mathrm{V}_{\mathrm{d}}-\frac{\mathrm{kT}}{\mathrm{q}}=\frac{\mathrm{E}_{\mathrm{g}}-\Phi_{\mathrm{m}}+\chi}{\mathrm{q}-\Phi_{\mathrm{F}}-\mathrm{V}_{\mathrm{y}}}
$$

şeklindedir. Burada, $\Phi_{\mathrm{m}}$ metal iş fonksiyonu, $\chi$ elektron yakınlığı, $\mathrm{E}_{\mathrm{g}}$ yasak enerji aralığı, $\Phi_{\mathrm{F}}$ Fermi enerjisi ve $V_{y}$ yalıtkan üzerinde düşen potansiyeldir. Arayüzey durumları mevcutken $V_{o}$ ile $V_{d}$ arasındaki ilişki,

$$
\mathrm{V}_{\mathrm{o}}=\left(\mathrm{V}_{\mathrm{d}}-\frac{\mathrm{kT}}{\mathrm{q}}\right)(1+\alpha)
$$

şeklinde verilir (Akkal ve ark., 2000). Arayüzey durumlarının etkileri dikkate alındığında $\mathrm{C}^{-2}-\mathrm{V}$ doğrusunun eğimi,

$$
\frac{d C^{-2}}{d V}=\frac{2}{q \varepsilon_{s} A^{2} N_{d}} \frac{1}{(1+\alpha)}
$$


ile verilir. Burada $\alpha=\mathrm{qN}_{\mathrm{ss}} \delta / \varepsilon_{\mathrm{i}}$ olup, $\mathrm{N}_{\mathrm{ss}}$, arayüzey durum yoğunluğu ve $\delta$, arayüzey tabakanın kalınlığıdır. $1 /(1+\alpha)=\mathrm{C}_{2}$ ifadesi tanımlanırsa $\mathrm{C}_{2}$, denklem (11) yardımıyla,

$$
\mathrm{C}_{2}=\frac{2}{\mathrm{q} \varepsilon_{\mathrm{s}} \mathrm{N}_{\mathrm{d}}^{\prime}\left(\frac{\mathrm{dC^{-2 }}}{\mathrm{dV}}\right)} \cong \frac{\mathrm{N}_{\mathrm{d}}}{\mathrm{N}_{\mathrm{d}}^{\prime}}=\frac{\varepsilon_{\mathrm{i}}}{\varepsilon_{\mathrm{i}}+\mathrm{qN}_{\mathrm{ss}} \delta}
$$

şeklinde yazılır. Burada $\mathrm{N}_{\mathrm{d}}{ }^{\prime}$, teorik verici yoğunluğudur. Bu çalışmada kullanılan n-tipi silisyum için verilen $1.2 \Omega$-cm'lik özdirenç ve $1450 \mathrm{~cm}^{2} / \mathrm{V}$-sn'lik mobilite değerleri kullanılarak $\mathrm{N}_{\mathrm{d}}^{\prime} 3.72 \times 10^{15} \mathrm{~cm}^{-}$ ${ }^{3}$ olarak bulunmuştur.

Şekil 6'daki $\mathrm{C}^{-2}-\mathrm{V}$ doğruların eğiminden 0,30 ve $60 \mathrm{kGy}$ radyasyon dozları için deneysel $\mathrm{N}_{\mathrm{d}}$ değerleri sırasıyla, $1.93 \times 10^{15}, 1.60 \times 10^{15}$ ve $1.35 \times 10^{15}$ bulunmuş olup, denklem (12) kullanılarak $\mathrm{C}_{2}$ değerleri elde edilmiştir. Radyasyon öncesi oda sıcaklığında hesaplanan $\mathrm{C}_{2}$ değeri 0.518 olup, bu değer arayüzey durumlarının mevcut olduğunu göstermektedir. Radyasyon öncesi oda sıcaklığında $\mathrm{Au} /$ koronen/n-Si/Al yapıları için $\delta=150 \AA$ ve $\alpha=0.927$ değerleri alındığında ortalama arayüzey durumları yoğunluğu $10.9 \times 10^{11} \mathrm{~cm}^{-2} \mathrm{eV}^{-1}$ bulunmuştur. Tüketme tabakasının genişliği $\left(\mathrm{W}_{\mathrm{D}}\right)$,

$$
\mathrm{W}_{\mathrm{D}}=\sqrt{\frac{2 \varepsilon_{\mathrm{s}} \varepsilon_{\mathrm{o}} \mathrm{V}_{\mathrm{d}}}{\mathrm{qN} N_{\mathrm{d}}}}
$$

ifadesi yardımıyla radyasyon öncesi oda sıcaklığında Au/koronen/n-Si/Al yapıları için $6385.2 \AA$ bulunmuştur. Fermi seviyesi sıcaklığa bağlı olarak,

$$
\Phi_{\mathrm{F}}=\frac{\mathrm{kT}}{\mathrm{q}} \operatorname{Ln}\left(\frac{\mathrm{N}_{\mathrm{c}}}{\mathrm{N}_{\mathrm{d}}}\right)
$$

bağıntısından hesaplanmıştır. $\mathrm{E}_{\mathrm{m}}$ ve $\Delta \Phi_{\mathrm{B}}$ sırasıyla,

$$
\mathrm{E}_{\mathrm{m}}=\mathrm{E}(\mathrm{x}=0)=\sqrt{\frac{2 \mathrm{qN} \mathrm{N}_{\mathrm{d}}}{\varepsilon_{\mathrm{s}} \varepsilon_{\mathrm{o}}}}
$$




$$
\Delta \Phi_{\mathrm{B}}=\sqrt{\frac{\mathrm{qE}_{\mathrm{m}}}{4 \pi \varepsilon_{\mathrm{s}} \varepsilon_{\mathrm{o}}}}
$$

bağıntıları yardımıyla radyasyon öncesi $1.88 \times 10^{4} \mathrm{Vcm}^{-1}$ ve $0.015 \mathrm{eV}$ olarak elde edilmiştir. $\mathrm{C}^{-2}$-V eğrisinden bulunan, $\Phi_{\mathrm{B}(\mathrm{C}-\mathrm{V})}$ parametresi, $\mathrm{V}_{\mathrm{d}}$, Fermi enerjisi $\left(\Phi_{\mathrm{F}}\right)$ ve $\Delta \Phi$ terimleri cinsinden,

$$
\Phi_{\mathrm{B}(\mathrm{C}-\mathrm{V})}=\mathrm{V}_{\mathrm{d}}+\Phi_{\mathrm{F}}-\Delta \Phi_{\mathrm{B}}
$$

şeklinde verilir. Burada $\Phi_{\mathrm{F}}$, gerçek Fermi enerji seviyesi $\left(\mathrm{E}_{\mathrm{i}}\right)$ ile fermi seviyesi $\left(\mathrm{E}_{\mathrm{F}}\right)$ arasındaki enerji farkıdır. Radyasyon öncesi oda sıcaklığında Au/koronen/n-Si/Al yapıları için engel yüksekliği 0.810 eV olup, radyasyon sonrası için diğer hesaplanan parametreler Tablo 3'de verilmiştir.

Tablo 3. Au/koronen/n-Si/Al yapılarının $\mathrm{C}^{-2}-\mathrm{V}$ eğrilerinden elde edilen radyasyon öncesi ve sonrası temel parametreler.

\begin{tabular}{|c|c|c|c|c|c|c|c|}
\hline $\begin{array}{c}\text { Doz } \\
(\mathrm{kGy})\end{array}$ & $\begin{array}{c}\mathrm{N}_{\mathrm{d}} \\
\left(\mathrm{x} 10^{15} \mathrm{~cm}^{-3}\right)\end{array}$ & $\begin{array}{c}\mathrm{V}_{\mathrm{d}} \\
(\mathrm{eV})\end{array}$ & $\begin{array}{c}\mathrm{W}_{\mathrm{D}} \\
(\AA)\end{array}$ & $\begin{array}{c}\Phi_{\mathrm{B}} \\
(\mathrm{eV})\end{array}$ & $\begin{array}{c}\mathrm{E}_{\mathrm{m}} \\
\left(\mathrm{x} 10^{4} \mathrm{Vcm}^{-1}\right)\end{array}$ & $\begin{array}{c}\Delta \Phi \\
(\mathrm{eV})\end{array}$ & $\mathrm{C}_{2}$ \\
\hline 0 & 1.93 & 0.590 & 6385.2 & 0.810 & 1.88 & 0.015 & 0.518 \\
30 & 1.60 & 0.245 & 4481.2 & 0.475 & 1.10 & 0.011 & 0.431 \\
60 & 1.35 & 0.230 & 4643.7 & 0.448 & 0.96 & 0.010 & 0.364 \\
\hline
\end{tabular}

Şekil 7'de Au/koronen/n-Si/Al yapılarının oda sıcaklığında -3 ile 5V aralığında alınmış iyonize radyasyon öncesine ve sonrasına ait iletkenlik-gerilim (G-V) eğrileri görülmektedir. Au/koronen/n$\mathrm{Si} / \mathrm{Al}$ yapılarının iletkenlik eğrilerine bakıldığında iyonize radyasyon sonrası iki durum görülmek olup, bunlardan birisi düşük voltaj değerlerine doğru kayma, diğeri ise azalma şeklindedir. Birinci durum, radyasyon ile elektron deşik çiftlerinin oluşumundan dolayı oksit yük yansımasına, ikinci durum ise arayüzey durumlarının ve tuzak merkezlerinin artmasına ve dolayısıyla da yarıiletkenin özdirencinin artmasına atfedilebilir (Karataş ve ark., 2006). 


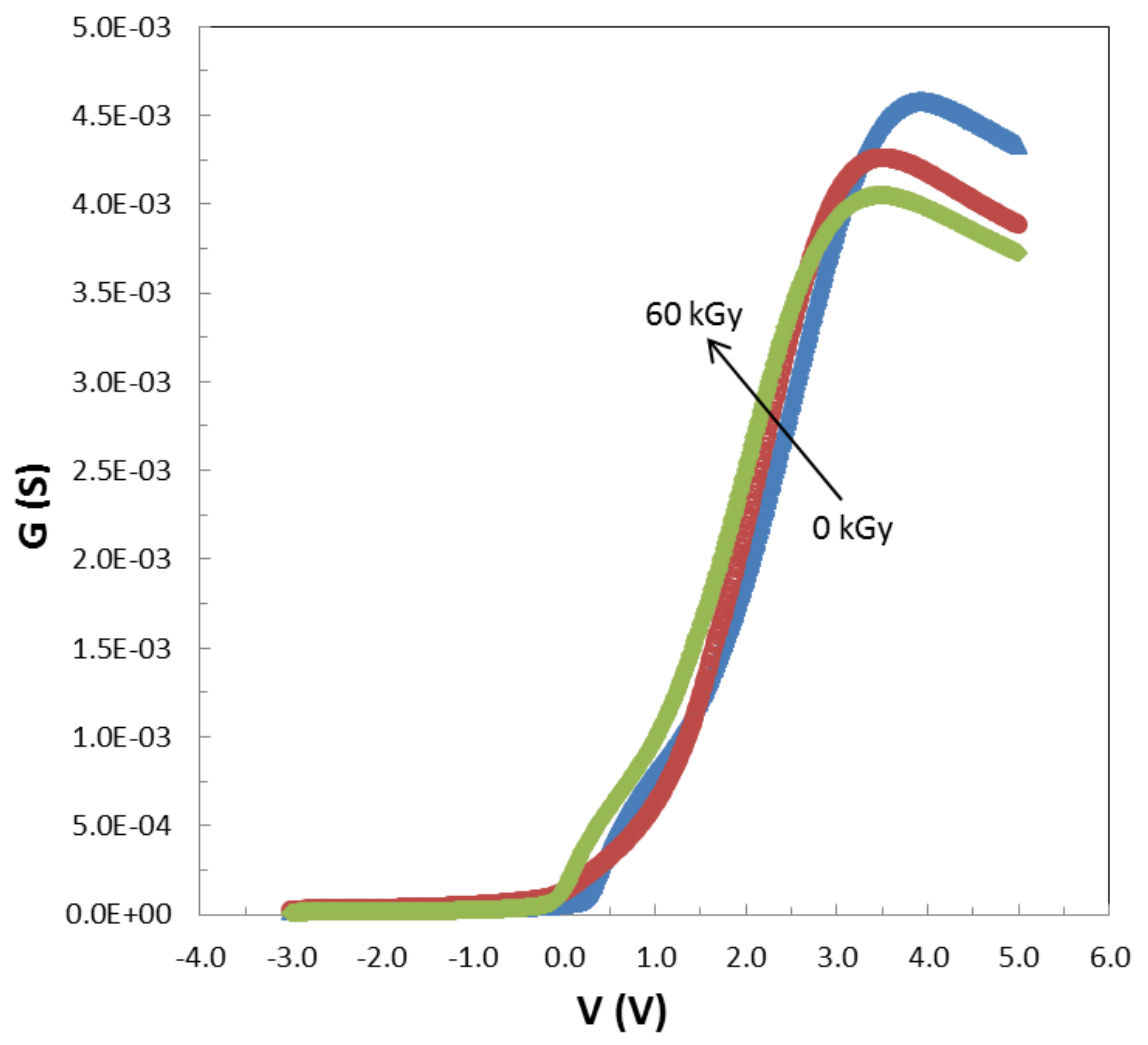

Şekil 7. Au/koronen/n-Si/Al yapılarının oda sıcaklığındaki radyasyon öncesi ve sonrası iletkenlik-gerilim eğrileri.

\section{Sonuçlar ve Öneriler}

$\mathrm{Bu}$ çalışmada güneş pilleri uygulamalarında kullanılan organik tabanlı Schottky yapıları üzerindeki iyonize radyasyonun etkileri incelenmiştir. Bunun için organik arayüzeyli Schottky yapıları üretilerek değişik dozlarda gama radyasyonuna maruz bırakılmış, karakterizasyon işlemleri yardımıla yapıların radyasyon öncesi ve sonrası bazı temel parametrelerindeki değişimler belirlenmiştir. Organik arayüzey olarak koronen malzemesi seçilmiş ve bu malzeme çeşitli kimyasal yöntemlerle temizlenmiş olan n-tipi silisyum alttabakalar üzerine kaplamak suretiyle Au/koronen/n$\mathrm{Si} / \mathrm{Al}$ organik arayüzeyli Schottky yapıları elde edilmiştir.

İyonize radyasyonun $\mathrm{Au} / \mathrm{koronen} / \mathrm{n}-\mathrm{Si} / \mathrm{Al}$ yapılarının düz beslem akım-gerilim eğrilerine sistematik bir etkisinin olduğu ve bu etkinin radyasyon dozuna bağlı olarak aygıt akımında bir azalma meydana getirdiği görülmüştür. Bu durum radyasyon sonrası organik/yariiletken arayüzeyindeki tuzakların artması sonucu serbest yük taşıyıcılarının tuzaklar tarafından yakalanmasına atfedilmiştir. Yapıların ideallik faktörünün 1'den çok büyük ve yarılogaritmik akım-gerilim eğrilerindeki lineer bölgenin çok küçük olması, yapıların akım mekanizmasında termiyonik emisyonunun yanında azınlık taşıyıcı enjeksiyonunun da etkin olması ihtimalini güçlendirmiştir. Gama radyasyonu dozunun kümülatif olarak artışı yapıların ideallik faktöründe artış, engel yüksekliğinde ise azalma meydana 
getirmiş olup, aygıt parametrelerindeki bu tür bozulmaların ışınlama sırasında tuzak formunda ve aktif olan gizli kusurlar tarafından oluştuğuna atfedilmiştir.

Deneysel sonuçlardan seri direncin artan radyasyon dozu ile artış gösterdiği görülmüştür. $\mathrm{Bu}$ durum iyonize radyasyon tarafından yaratılan kusurlar yüzünden serbest taşıyıcı üretiminin azaldığını ve dolayısıyla da yarıiletkenin özdirencinin arttığını göstermiştir.

Gama radyasyonu, üretilen yapılarda boşlukların ve diğer kusurların oluşmasına sebep olmuş ve bu da arayüzey durum yoğunluklarını arttırmıştır.

Metal/yarıiletken arayüzeyindeki dielektrik sabitinde oluşan değişim veya iyonize katk1 konsantrasyonunun radyasyon etkisine bağlı olarak azalması, Au/koronen/n-Si/Al yapılarının radyasyon sonrası kapasite değerlerinde azalma meydana getirmiştir.

İyonize radyasyon, arayüzey durumlarını ve tuzak merkezlerini arttırmak suretiyle yarıiletkenin özdirencinin artmasına sebep olmuş ve bunun sonucunda da Au/koronen/n-Si/Al Schottky yapılarının iletkenlikleri azalmıştır.

$\mathrm{Bu}$ çalışmadaki deneysel sonuçlardan elde edilen veriler sayesinde radyasyon ortamında çalıştırılacak olan organik tabanlı bir güneş pili hücresinin davranışı önceden tahmin edilebilecek ve radyasyon etkisiyle değişen performans parametreleri göz önünde bulundurularak aygıt tasarımları yapılabilecektir. Diğer taraftan üretilen $\mathrm{Au} /$ koronen/n-Si/Al organik tabanlı Schottky aygıtlarının düşük doz radyasyon sensörü uygulamaları için uygun olduğu ve bazı elektriksel parametrelerinin uygulanan radyasyon dozuna bağlı olarak değiştirilip kontrol edilebileceği görülmüştür.

\section{Teşekkür}

Bu çalışma Giresun Üniversitesi Bilimsel Araştırma Projeleri Ofisi tarafından FEN-BAP-A170417-85 nolu proje ile desteklenmiştir.

\section{Yazarların Katkısı}

Tüm yazarlar çalışmaya eşit katkıda bulunmuştur.

\section{Çıkar Çatışması Beyanı}

Yazarlar arasında herhangi bir çıkar çatışması bulunmamaktadır. 


\section{Araştırma ve Yayın Etiği Beyanı}

Yapılan çalışmada araştırma ve yayın etiğine uyulmuştur.

\section{Kaynaklar}

Akkal, B., Benamara, A., Gruzza, B. and Bideux, L. (2000). Characterization of interface states at $\mathrm{Au} / \mathrm{InSb} / \mathrm{InP}(100)$ Schottky barrier diodes as a function of frequency. Vacuum, 57, 219-228.

Arshak, K., Korostynska, O. (2004). Thick film oxide diode structures for personal dosimetry application. Sensors and Actuators, A 113, 319-323.

Auret, F. D., Goodman, S. A., Meyer, W. E., Erasmus, R. M., Myburg, G. (1993). Deep level transient spectroscopy characterization of electron irradiation induced hole traps in $\mathrm{p}$-GaAs grown by molecular beam epitaxy, Japanese Journal Of Applied Physics, Pt. 2, Letters 32, L974eL977.

Auret, F. D. Wilson, A., Goodman, S. A., Myburg, G., Meyer, W. E. (1994). Electrical characteristics of neutron irradiation induced defects in n-GaAs, Nuclear Instruments \& Methods In Physics Research Section B-Beam Interactions With Materials And Atoms, 90, 387e391.

Barış, B., Karadeniz, S., Erdal, M. O. (2017). Preparation of koronen nanowires and its properties. Materials Letters, 205, 70-74.

Bohlin, K. E. (1986). Generalized Norde plot including determination of the ideality factor. Journal of Applied Physics, 60, 1223-1224.

Card, H. C., Rhoderick, E. H. (1971). Studies of tunnel MOS diodes I. Interface effects in silicon Schottky diodes. Journal of Physics, D4, 1589.

Erdal, M. O. (2020). Photoresponse properties of coronene nanowires thin-film-based photodiode. Journal of Materials Science:Materials in Electronics, 31, 18980-18987.

Fetzer, J. C. (2000). The Chemistry and Analysis of the Large Polycyclic Aromatic Hydrocarbons. Wiley, New York.

Gregor, D. M., Christof, W. (2004). Growth of aromatic molecules on solid substrates for applications in organic electronics. Journal Of Materials Research, 19, 1889.

Grussell, E., Berg, S. and Andersson, L. P. (1980). Electrical Defects in Silicon Introduced by Sputtering and Sputter-Etching. Journal of The Electrochemical Society, 127, 1573.

Itoh, T. (2008). Multiple fluorescence and the electronic relaxation processes of koronen vapor: The fluorescence from the S1, S2, and S3 states. Journal Of Molecular Spectroscopy, 252, 115.

Jiang, W., Li Y., Wang, Z. (2013). Heteroarenes as high performance organic semiconductors. Chemical Society Reviews, 42, 6113.

Jun, M., Jang, M., Kim, Y., Choi, C., Kim, T., Park, B. and Lee, S. (2007). Analysis of interface trap states at Schottky diode by using equivalent circuit modeling. Journal Of Vacuum Science \& Technology B, 25, 82.

Kar, S., Ashok, S. and Fonash, S. (1980). Evidence of tunnel-assisted transport in nondegenerate MOS and semiconductor-oxide-semiconductor diodes at room temperature. Journal of Applied Physics, 51, 34173421.

Kar, S. and Varma, S. (1985). Determination of silicon-silicon dioxide interface state properties from admittance measurements under illumination. Journal of Applied Physics, 58; 4256-4266.

Karatas, S., Turut, A. and Altindal, S. (2005). Effects of 60Co $\gamma$-ray irradiation on the electrical characteristics of Au/n-GaAs (MS) structures. Nuclear Instruments \& Methods A, 555, 260.

Karataş, Ş., Türüt, A. (2006). Electrical properties of Sn/p-Si (MS) Schottky barrier diodes to be exposed to 60Co g-ray source. Nuclear Instruments and Methods in Physics Research A, 566, 584-589.

Kido, J., Hongawa, K., Okuyama, K., Nagai, K. (1994). White light-emitting organic electroluminescent devices using the poly(N-vinylcarbazole) emitter layer doped with three fluorescent dyes. Applied Physics Letters, 64, 815.

Lin, Z. Yi-Men, Z., Yu-Ming, Z., Chao, H. (2010). Neutron radiation effect on 4H-SiC MESFETs and SBDs. Journal of Semiconductors, 31, 114006. 
Mamor, M., Sellai, A., Bouziane, K., Al. Harthi, S. H., Al. Busaidi, M. and Gard, F. S. (2007). Influence of He-ion irradiation on the characteristics of $\mathrm{Pd} / \mathrm{n}-\mathrm{Si} 0.90 \mathrm{Ge} 0.10 / \mathrm{Si}$ Schottky contacts. Journal Of Physics D-Applied Physics, 40, 1351.

Mott, N. F. (1938). Note on the contact between a metal and an insulator or semi-conductor. Proceedings of Cambridge Philosophical Society, Vol. 34, 568-572.

Mott, N. F. (1939). Proceedings of the Royal Society of London. Series A, Mathematical and Physical Sciences Vol. 171, No. 944, 27-38.

Nicollian, E. H. and Brews, J. R. (1982). Metal Oxide Semiconductor (MOS) Physics and Technology. John Wiley, New York.

Payanan, T., Leepipatpiboon, N., Varanusupakul, P. (2013). Low-temperature cleanup with solid-phase extraction for the determination of polycyclic aromatic hydrocarbons in edible oils by reversed phase liquid chromatography with fluorescence detection. Food Chemistry, 141, 2720.

Rawa-Adkonis, M., Wolska, L., Namiesnik, J. (2006). Analytical Procedures for PAH and PCB Determination in Water Samples-Error Sources. Critical Reviews In Analytical Chemistry, 36, 63.

Rhoderic, E. M. and Williams, R. H. (1988). Metal Semiconductor Contacts. 2nd Ed. Clarendon and Oxford.

Ruifeng, Z., Haipeng, Z., Jiacong, S. (1999). Blue light-emitting diodes based on koronen-doped polymers. Synthetic Metals, 105, 49.

Saqri, N., Felix, Al J.F., Aziz, M., Jameel, D., Araujo, C.I.L., Albalawi, H. et al. (2015). Investigation of the effects of gamma radiation on the electrical properties of dilute GaAs1 xNx layers grown by molecular beam epitaxy, Current Applied Physics, 15, 1230e1237.

Schottky, W. (1938). Halbleitertheorie der Sperrschicht. Naturwissenschaften, Vol. 26, 843.

Singh, A. (1985). Characterization of interface states at $\mathrm{Ni} / \mathrm{nCdF}_{2}$ Schottky barrier type diodes and the effect of $\mathrm{CdF}_{2}$ surface preparation. Solid-State Electron, 28, 223.

Singh, R., Arora, S. K. and Kanjilal, D. (2001). Swift heavy ion irradiation induced modification of electrical characteristics of Au/n-Si Schottky barrier diode. Materials Sclence In Semiconductor Processing, 4, 425.

Tataroglu, A, Altindal, S and Bulbul, M. (2006). 60Co $\gamma$ irradiation effects on the current-voltage (I-V) characteristics of $\mathrm{Al} / \mathrm{SiO} 2 / \mathrm{p}-\mathrm{Si}$ (MIS) Schottky diodes. Nuclear Instruments \& Methods In Physics Research A, 568, 863-868.

Xiao, J., Yang, H., Yin, Z., Guo, J., Boey, F., Zhang, H., Zhang, Q. (2011). Preparation, characterization, and photoswitching/light-emitting behaviors of koronen nanowires. Journal Of Materials Chemistry, 21, 1423.

Yıldırım, M. (2017). Determination of Contact Parameters of Au/n-Ge Schottky Barrier Diode with Rubrene Interlayer. Journal of Polytechnic, 20, 165.

Yüksel, Ö. F., Tugluoglu, N, Calıskan, F., Y1ldırım, M. (2016). Temperature Dependence of Current-Voltage Characteristics of Al/Rubrene/n-GaAs (100) Schottky Barrier Diodes. Materials Today, 3, 1271.

Yüksel, Ö. F., Kus, M., Yıldırım, M. (2017). Capacitance and Conductance-Frequency Characteristics of $\mathrm{Au} / \mathrm{n}$-Si Schottky Structure with Perylene-Diimide (PDI) Organic Interlayer. Journal of Electronic Materials, 46, 882.

Zhang, R., Zheng, H., Shen, J. (1999). Blue light-emitting diodes based on koronen-doped polymers. Synthetic Metals, 105, 49.

Zhan, C., Jiang Y. Y., Yang, M. Y., Lu, L. H., Xiao, S. Q. (2014). Synthesis and optoelectronic properties of a novel molecular semiconductor of dithieno[5,6-b:11,12-b']koronen-2,3,8,9-tetracarboxylic tetraester. Chinese Chemical Letters, 25, 65. 